\title{
La servidumbre y la muerte Notas para el estudio de los suicidios de esclavos en Brasil siglo XIX
}

\author{
Servitude and Death \\ Notes for the Study of Suicides Slaves in Brazil in \\ 19th Century
}

\begin{abstract}
RESUMEN
Los suicidios de los esclavos en Brasil ponen en escena distintos sentidos y múltiples dinámicas culturales. A menudo pensada solo como forma de resistencia a su condición de servidumbre, la muerte voluntaria del esclavo muestra caras diversas cuando es interrogada desde varios puntos de vista. Este artículo pretende exponer el amplio y complejo repertorio de motivaciones atribuido a la auto-aniquilación dentro del grupo esclavo en los territorios brasileros en el siglo XIX, haciendo énfasis en que, si bien la condición de ser esclavo desencadenó a menudo el acto trágico, hubo también una gama variada de circunstancias que lo produjeron. El artículo se basa en una re-lectura fructífera de una interesante producción historiográfica brasilera al respecto, escrita a su vez, a partir de la prensa o de los registros policiales y que se centran en las provincias de Bahía y Sao Paulo y en las ciudades de Juiz de Fora y Recife.
\end{abstract}

Palabras Clave: Esclavitud - Brasil - Siglo XIX - Suicidio - Homicidio De Sí Mismo

\begin{abstract}
The suicides of slaves in Brazil put on different directions and multiple cultural dynamics. Often, thought only as a form of resistance to their servitude condition, slave voluntary death shows different faces when questioned from several points of view. This article aims to show the wide and complex repertoire of motivations attributed to self-annihilation in the Brazilians slaves in the nineteenth century, emphasizing that while the condition of being a slave triggered often tragic act, there was also a wide range of circumstances that produced it. The article is based on a fruitful re-reading of an interesting Brazilian historiographic production about it, written in turn, from the press or police records and which focuses on the provinces of Bahia and Sao Paulo and cities of Juiz de Fora and Recife.
\end{abstract}

Keywords: Slavery - Brazil - 19th Century - Suicide - Self-Killing

* Doctora en Historia de la Université Paris 1, Panthéon-Sorbonne. DEA en Historia y Civilizaciones, École des Hautes Études en Sciences Sociales. CV: https://scienti.colciencias.gov.co/cvlac/visualizador/ generarCurriculoCv.do?cod_rh=0000606855. 
n Salvador de Bahía, el esclavo Timoteo decidió quitarse la vida en 1861. Pertenecía a la viuda Clara Joana Rosa dos Santos, había sido criado y educado en casa de sus amos, sabía leer y escribir, incluso dejó una carta pidiendo perdón y explicando los motivos de su acto (Ferreira, 2004, p. 216-217). Días atrás, su ama le había anunciado que lo vendería, pero Timoteo no quería ser ofrecido en plaza pública, pues de ello podría resultar su transferencia para otro lugar. Después de suplicar a su dueña, sin éxito, que cambiara de opinión, el esclavo se dio muerte (Ferreira, 2004, p. 213).

Este caso ilustra uno de los motivos que se han esgrimido para dar cuenta de la conducta suicida entre los esclavos: no querer ser desplazados, desarraigados de su lugar habitual de vida y trabajo. El problema del suicidio, entre cualquier grupo social, pone en escena diversas variables, pero la condición de esclavo agrega aspectos específicos, adicionales, que no están presentes cuando se trata de la conducta suicida en otros grupos de la población americana durante el siglo XIX.

Identificar los motivos por los cuales los esclavos se suicidaban en esta época y territorio es un reto complejo; el suicidio es, a la vez, un acto individual y un acto social. Las razones atribuidas a esta conducta por quienes debían tramitarla socialmente: sacerdotes, jueces, letrados, policías (y en ocasiones los mismos esclavos, amigos o familiares de quien se mataba) permiten conocer cuáles eran los focos de tensión y conflicto en la sociedad esclavista considerada; los testimonios recogidos por las autoridades y la prensa indican la naturaleza de las normas vigentes en una sociedad, y su forma de concebir la muerte o ciertos tipos de muerte.

En general, los testimonios de las personas cercanas a los esclavos suicidas aportan una vaga idea de los motivos de esta conducta. A veces es una explicación confusa porque no todo está dicho, no todo se sabe. En ocasiones, los motivos son varios, uno esconde otro más profundo. El suicidio se inscribe en una historia personal de la cual las fuentes revelan, borrosamente, pocos aspectos. El incidente que precipita al individuo en la desesperación sucede a otras desgracias, a otras decepciones, a otras frustraciones desconocidas. Una buena parte de las razones profundas que conducen a un hombre o a una mujer a terminar con su vida permanece en una zona inaccesible para la familia, los parientes, los vecinos, para las autoridades o para el cirujano que lo reconocen, pero más aún para el historiador. Las razones pertenecen solo a quienes terminaron con su vida, ellas forman una parte íntima de su historia singular, de la cual ellos son, al final, los únicos depositarios. Sin embargo, a pesar de lo íntimo, secreto y recóndito que puedan ser los motivos, no escapan completamente al vínculo social, al grupo, a la cultura, a la época donde se inscriben (Godineau, 2012, p. 119).

Aquello que los testigos o las autoridades presentaban como una explicación posible, ofrece al historiador indicios sobre lo que las personas consideraban motivo de consternación suficiente para realizar ese acto. Ellos dicen lo que en ese grupo, época y lugar se suponía que volvía la vida insoportable, insufrible, y que iba más allá de la condición o experiencia de ser esclavo, lo que no fue para todos intolerable.

Una de las facetas de la complejidad de la pregunta por el "por qué", tiene que ver con que la conducta de los individuos a veces pude ser confusa y equívoca incluso para sí mismos, 
de ahí la dificultad de mostrarla transparente para las autoridades, los familiares o los amos. Las explicaciones del comportamiento no están limitadas a la racionalización de la conducta -donde se presume que el actor entiende lo que hace y por qué lo hace-.

Concebir un repertorio motivacional y no un motivo, único, del acto suicida, se fundamenta en la idea de que el esclavo posee un margen de acción, unos "espacios de maniobra" (Chalhoub, 2011, p. 40), que le permiten tomar ciertas decisiones y que tiene un lugar como actor en el proceso histórico. En este sentido la reflexión considera el esclavo, no como una "cosa poseída" en una estructura que existía independientemente de él, sino como actor de su destino en la medida de las posibilidades existentes. Ellos desarrollaron formas específicas de hacer sociedad -estructuras familiares de asentamiento, empleo y transformación de recursos naturales, diferentes maneras de interpretar el mundo-, además del brío y la complejidad de tales invenciones, actuaron con firmeza en contra de la subordinación (Mosquera, Pardo \& Hoffman, 2002, p. 14).

El fenómeno del suicidio y las motivaciones que el esclavo y/o su grupo social ofrecen a esta conducta se explorará en el Brasil del siglo XIX, a partir de una lectura sintética de varios trabajos académicos y publicaciones universitarias que se han realizado en el país al respecto. La esclavitud es uno de los aspectos fundamentales a la hora de considerar la formación de la sociedad americana entre los siglos XVI y XIX. Fue trascendental en la construcción de sincretismos religiosos, de formas de producción, de instituciones políticas, de estructuras demográficas, entre otros. La esclavitud tenía elementos comunes en muy variados contextos: en casi todas partes los esclavos tuvieron familias, crearon economías propias, desplegaron destrezas para la manumisión (Valencia, 2008, p. 237), idearon formas de convivencia social y cultural, inventaron diversas estrategias de negociación (Valencia, 2003, p. 37; Florentino, 1997, p. 49).

Si bien la esclavitud, como institución, era una, existieron hondas diferencias entre las distintas colonias del mundo ibérico. Brasil fue quizá el país con mayor número de esclavos en todo el mundo, fue un lugar trascendental de tráfico negrero, que articulaba todo el Atlántico sur, con rutas que partían de África y terminaban en el interior de América del Sur (Valencia, 2008, p. 23-24).

No es fácil hallar fuentes para el estudio del suicidio. Aún en la actualidad, la muerte voluntaria es tabú - objeto de prohibición tradicional que transmite una obligación moral -, algo sobre lo que no se habla, que se mantiene en silencio, que pertenece a la dimensión de lo sagrado. Además, muchas veces la causa de la muerte no se denunciaba o se ocultaba intencionalmente por las penas de índole corporal y pecuniaria que la justicia establecía para las tentativas o los suicidios consumados. Es posible pensar también en el ocultamiento de casos para evitar sanciones morales o religiosas, y muertes voluntarias que se simulan como accidentes. La escasez de fuentes también puede atribuirse a la poca eficacia de la administración de justicia (parsimonia de comunicaciones, negligencia de funcionarios, falta de jueces). A pesar de ello, fue posible hacer una re-lectura valiosa de una sugestiva producción historiográfica brasilera sobre el tema, escrita, a partir de la prensa o de los registros policiales. Cada una de estas fuentes aporta visiones e informaciones de distinta naturaleza sobre el 
fenómeno explorado.

La prensa muestra algunas de las tensiones que atravesaban esta sociedad, signadas por el odio, la desesperación, la venganza, la violencia. También es un recurso para comprender las transformaciones sociales y para reconstruir los cambios respecto a un problema específico como el aquí tratado. Por otro lado, los archivos policiales y judiciales resultan fértiles para el trabajo del historiador, pues son lugares de expresión, no sólo de relaciones de poder, sino de representaciones culturales y sociales, y de los tejidos emocionales vigentes en un momento y territorio específicos. Allí se hace evidente el establecimiento de lo que es considerado permitido o prohibido, justo o injusto, falso o veraz, simulado o auténtico (Argouse, 2013, p. 1-3).

\section{Un concepto moderno}

Se entenderá el suicidio como la muerte que se produce un esclavo a sí mismo, con consciencia de la acción y por su propia voluntad (Falret, 1822, p. 3). La definición dada por Émile Durkheim en su famosa obra El suicidio (1897), se convirtió en canónica: "Se llama suicidio toda muerte que resulte mediata o inmediatamente de un acto, positivo o negativo, realizado por la misma víctima" (Durkheim, 1897, p. 13). Pero más allá de su definición clásica, Durkheim reserva una categoría para el suicidio esclavo, "el suicidio fatalista", por oposición al anómico. Fatalista sería aquel que se produce debido a una regulación excesiva y por una integración insuficiente (Durkheim, 1897, p. 142). Sin embargo, como se verá, no todo esclavo se mata, en estricto sentido, para escapar al yugo de su amo. Entre todos los esclavizados que, dada su condición, tendrían razones para matarse, solo lo hacen los más irritables, los más vulnerables, los más sensibles, quienes son poco capaces de controlarse; o quienes tuvieron amos más crueles y brutales - pues no todos lo fueron-.

El suicidio es un concepto moderno que nombra una práctica milenaria (Godineau, 2005, p. 126). En inglés (suicide), la palabra surgió solo alrededor de 1650 y en las lenguas francesa o italiana no lo hizo antes del siglo XVIII (Griffin, 1986, p. 64-77). En portugués y español, lenguas provenientes del latín vulgar, lo que hoy conocemos como "suicidio», se designaba con la expresión "pessoa que se mata a si propia" u "homicidio de (contra) sí mismo", hasta el siglo XVIII. ${ }^{1}$ Para el pensamiento cristiano, la muerte voluntaria era un crimen contra la sociedad y contra Dios; además, quien se daba muerte no era considerado una víctima sino un criminal. La invención de la palabra suicidio, a juicio de algunos autores, reflejaría una persecución penal menos rigurosa del "homicidio de sí mismo" y un hito en el proceso histórico de su patologización y su despenalización (Bähr, 2013, p. 620-632). A pesar de la aparición del neologismo, la estigmatización social hacia esta conducta transgresora no desapareció, solo sufrió algunas transformaciones en ciertas sociedades (Brancaccio; Engstrom \& Lederer, 2013, p. 607-619).

La manera como una sociedad enjuicia el acto suicida es significativa. En los tribunales

1 Suicidio: Causar a morte a si proprio. Fig. Arruinar-se por culpa propria. (Do lat. sui + caedere) suicıdio, (su-i) m. Acto ou effeito de suicidar-se" (Figueiredo, 1913, p.1905). 
criminales de la época en América ibérica, se penalizaba tanto la tentativa como el suicidio consumado; es claro que si se había cometido un intento de suicidio, la acusación caía sobre el individuo, aún vivo; pero en el otro caso, la pena se aplicaba al cadáver y a la memoria del fallecido. Luego del proceso, el difunto era reconocido como inocente cuando se confirmaba su estado de locura en el momento de cometer el acto, si no, se le inculpaba y condenaba. Esta consideración se basa en la idea de que no hay responsabilidad en la locura, y por ello se exime de la pena a quien actúa contra la ley en estado de alienación.

Las leyes criminales y eclesiásticas prescribian penas para el suicida. Algunas recaían sobre sus bienes --que se embargaban-, y otras sobre su cadáver y su memoria. La Iglesia católica también suprimía los ritos funerarios. Considerado como una desviación capital, el suicidio tenía como consecuencia un poderoso ritual de regulación social que comprendía el arrastre y la exhibición del cadáver del suicida, antes de conducirlo a los extramuros de las ciudades, donde era quemado en una hoguera o dejado a la intemperie para que fuera alimento de las aves carroñeras. Estas penas podrían hoy considerarse absurdas, pero adquieren sentido si se piensa que hasta hace muy poco, el cadáver era aún considerado persona. No es fácil resignarse a tratar el cuerpo del fallecido como una cosa con la cual, al igual que con todos los otros objetos, se pueden romper vínculos fácil y simplemente. La idea de que un resto de vida anima el cadáver por cierto tiempo, a veces largo, está presente en algunas sociedades. El cadáver es a la vez un muerto y un vivo. Las gentes están persuadidas de que el muerto continúa viviendo de cierta manera, por ello lo cuidan, lo vigilan. Además, la relativa similitud entre un cadáver y alguien que duerme deja pensar que la muerte podría ser solo un sueño prolongado (Thomas, 2006, p. 12-17).

\section{Un conjunto de motivos}

No hay un suicidio esclavo, sino suicidios esclavos. Los cautivos que se dan muerte, sus contrariedades y los contextos en los cuales se hallan, el sentido que quieren dar a su acto, el objetivo que persiguen, así como los factores que favorecen a su decisión son múltiples. Diversas teorías, sociológicas, biológicas, psicológicas y filosóficas del suicidio muestran con elocuencia la complejidad de esta conducta.

Aunque no se tratará en extenso este problema aquí, algunos autores señalaron la posible predisposición "biológica" al suicidio en ciertos grupos culturales africanos que vinieron esclavizados a América. Durante la primera mitad del siglo XX, el antropólogo y jurista cubano Fernando Ortiz - formado en la escuela criminal lombrosiana - sostuvo con ahínco esta posición y señaló esta predisposición en los lucumíes (yorubas); y la del antropólogo francés Henri Dumont, quien trataba sobre esa tendencia entre los lucumies, los dajomés, los biches, los carabalís y los bisayos (Ortiz, 1916, p. 394; La Rosa, 2003, p. 175-182). En México, la misma cuestión fue planteada por Gonzalo Aguirre Beltrán (Aguirre, 1989, p. 180-183), quien hace eco de las afirmaciones que en ese sentido sostenía el letrado martiniqués Médéric Louis Élie Moreau de Saint-Méry (1797), según las cuales los fantía estaban predispuestos a cometer 
suicidio, tanto como los ibo (Midy, 2006, p. 173-201), los guineos, los mina y los arará. Se ha planteado más recientemente la explicación de que no se trata de ninguna predisposición biológica, sino de que estos grupos tienen concepciones de la muerte y de la resurrección que hacen posible, pensable y aún deseable la práctica de autoeliminación (Stevenson, 1985; Goody, 1962; M'bokolo, 2009), también se ha esgrimido el argumento de que se trataría de la observancia de códigos morales ancestrales, que instaban a los africanos a morir antes que sufrir la indignidad o la ignominia. Otras interpretaciones muestran que los esclavos recurren al suicidio en respuesta a un deterioro en sus circunstancias de vida o por expectativas incumplidas (Kneeland, 2006, p. 8), lo que quizás pueda verse en algunos de los casos de situaciones permanentes de cautiverio, narrados en la segunda parte de este escrito.

La reflexión sobre los actos de auto-aniquilación recorrerá dos períodos del itinerario de un esclavo. Partirá del momento de la travesía interoceánica en el barco negrero y luego se detendrá cuando el esclavo - bozal o criollo- estaba ya al servicio de un amo.

\section{Suicidio en la travesía atlántica}

Tanto antes como durante la travesía, los esclavos capturados se suicidaban, lo que preocupaba mucho a los comerciantes por lo que ello significaba en términos de pérdida económica. La experiencia de la travesía atlántica para los esclavos estuvo signada por condiciones sanitarias deficientes, poca agua y comida, casi ninguna posibilidad de movimiento corporal, violencia y agresiones de toda índole, rebeliones a bordo y también suicidios (Toyin \& Warnock, 2007, p. XXII). Desde el comienzo de la trata, maestres, marineros y mercaderes intercambiaban relatos sobre el suicidio de los esclavos durante el recorrido marítimo.

El trauma que representó el pasaje transatlántico ha sido objeto de innumerables discusiones, relacionadas con la influencia de la esclavitud transatlántica en las sociedades americanas (Lovejoy, 2008, p. 14-19). Los esclavos, en general, fallecían en proporciones directamente relacionadas con la duración de la travesía oceánica, hubo patrones distintos de "pérdidas en tránsito", de acuerdo con la región africana de embarque de los capturados. (Florentino, Vieira \& Domingues, 2004, p. 83-126). Los barcos negreros portugueses eran llamados tumbeiros, para señalar que eran lugares donde venían cadáveres (M'bokolo, 2009, p. 301-302.).

El rapto, la emigración impuesta, la violencia, el hambre y la separación de la familia dieron a los esclavos motivos suficientes para las reacciones suicidas (Ortiz, 1916, p. 359). Desde el comienzo de la trata, maestres, marineros y mercaderes intercambiaban relatos sobre el suicidio de los esclavos durante el recorrido marítimo. Muchos anotaban alarmados que los cautivos africanos respondían a la esclavización matándose (Snyder, 2010, p. 39). En los lugares de carga de esclavos de las costas africanas y durante el viaje en los barcos, los cautivos se suicidaban tanto que fue necesario utilizar ciertas "tecnologías" para prevenirlo. Los esclavos se colocaban en redes colgadas de las cubiertas de los barcos y se mantenían con grilletes. Se 
empleó asimismo el speculum oris, ${ }^{2}$ instrumento puesto en la boca del esclavo, que le mantenía abiertas las mandíbulas a la fuerza, para obligarlo a comer en caso de que quisiera dejarse morir de hambre y de sed (Rediker, 2011, p. 26; Smallwood, 2008, p. 141). Se tiene noticia también, de que cuando los esclavos rehusaban alimentarse, se les quemaban los labios con carbón ardiente, con la amenaza de hacerles comer esos carbones si persistían en su negativa (Ortiz, 1916, p. 145). Como parte de las medidas preventivas del suicidio, los comerciantes privaban a los esclavos de movimiento, incluso les ponían unas "mordazas en forma de cruz de madera" para que no acudieran al procedimiento letal de "tragarse la lengua" (Ortiz, 1916, p. 393). Esa manera de suicidarse acontecía más en los navíos, según relatan historiadores y novelistas, pero también se presentaba en otros momentos y situaciones de la vida esclava. "Tragarse la lengua" equivale a dejar de respirar, es decir, producirse, voluntariamente, una suerte de asfixia.

Las espantosas condiciones del viaje interoceánico eran conocidas desde hacía tiempo (Puig-Samper, 2017, p. 71). El sacerdote jesuita Alonso de Sandoval (1576-1652), establecido en el puerto de Cartagena de Indias, describía de esta manera las condiciones en las que viajaban los esclavos hacia América en el siglo XVII. Decía que los recién cautivos sufrían "de tan grande tristeza y melancolía", que unidas a la "persuasión de que una vez arribados se iba a hacer aceite con ellos", los llevaba a producirse la muerte (Sandoval, 1987, s. p). La tristeza y la melancolía de los esclavos aparecen a menudo para explicar el acto suicida, como se apreciará más adelante. En ocasiones, cuando los comerciantes veían que la nostalgia entristecía a los negros los obligaban a bailar y a cantar para conjurarla. Si se resistían, el látigo los forzaba (Ortiz, 1916, p. 394; Falconbridge, 1788 , p. 23). La llamada "melancolía fija" hacía estragos en los barcos. En ocasiones, a pesar de que los esclavos estuvieran relativamente bien alimentados y bien tratados, morían porque, simplemente, habían perdido las ganas de vivir. Esta melancolía se caracterizaba por letargo, desánimo, abatimiento y total inapetencia (Toyin \& Warnock, 2007, p. 261).

Llama la atención la similitud de este estado de abatimiento mencionado por Sandoval y luego por numerosos autores, en relación con los esclavos, con lo que algunos historiadores llaman el "desgano vital", que se ha señalado como una de las causas de la catástrofe demográfica americana después de la llegada de los europeos. El desgano vital se pensaba también como una situación de profunda crisis anímica, producida por el brutal choque cultural que supuso la Conquista y por la ruptura con las formas de vivir tradicionales que habían ritmado su presencia en el mundo desde tiempos antiguos (Sánchez, 1990, p. 22).

Cuando se piensa en la melancolía de los esclavos, debe también tenerse en cuenta la imagen del mar en algunos sistemas simbólicos y en el miedo que inspiraba. Para ciertas culturas africanas, el mar, por su extensión, su profundidad, su carácter insondable y, en ocasiones, su violencia "natural", recordaba la ira divina o las ferocidades diabólicas. Se tenía la creencia en algunas culturas de que el demonio se escondía en el fondo del mar, se imaginaba que monstruos inicuos vivían en las entrañas del océano (Tempère, 2011, p. 2). La valoración negativa, temible, del mar, concebido como lugar de la muerte y de los muertos, en algunas

2 El speculum oris era un instrumento que impedía el cierre de la boca (Harris, 1849, p. 680). 
comunidades africanas, intensificaría la aprensión y el desasosiego de quienes emprendían, cautivos, el viaje. Los valores psicológicos que estas comunidades proyectaban en el mar fueron numerosos. El mar fue la última morada de gran número de esclavos; los navíos negreros sobrecargados o muy viejos se hundían alli; otros fueron invadidos y vencidos durante combates navales; otros aún arrojaban al mar a los esclavos cuando era preciso disminuir el peso de la embarcación. Además, se ha visto ya como las condiciones de la travesía eran espeluznantes. El mar se mostraba así como una fuente de peligro y de muerte, como un sudario (Devisse, 1989, p. 397-418).

El temor al mar, común a varias culturas, se expresó de diversas maneras durante mucho tiempo y adquiere una relevancia significativa en el relato de un célebre esclavo: Mahommah Gardo Baquaqua, quien nació en Djougou, en la Bahía de Benín, aproximadamente en 1824 (Rich et al., 2012, p. 381). Llegó a Brasil como esclavo en 1845, su periodo de esclavitud duró dos años, obtuvo su libertad en la ciudad de Nueva York. Luego partió a Haití, donde sobrevivieron algunos informes de sus experiencias, habló sobre sus vivencias de la esclavitud en varias conferencias sobre abolicionismo en el estado de Nueva York y en el de Pennsylvania; además se han encontrado numerosas cartas escritas por él (Moore, 1854, p. 40-57; Lara, 1988, p. 269-284). Se desconoce la fecha de su muerte, después de 1857 se perdió su rastro. Baquaqua escribió su autobiografía en Chatham (hoy Ontario) en 1855 y la publicó en Detroit el mismo año (Lovejoy, 2008, p. 14-19).

En ella, Baquaqua narra las desgracias que padeció y que vio soportar a sus compañeros de cautiverio en la travesía, durante la cual, "fui colocado en el más horrible de los lugares", escribe. Rememora el maltrato, el látigo, los grillos, las cadenas, la inmovilización, los hombres apiñados desnudos, precipitados en el suelo del sótano del barco, el hambre y la sed. Además, la "repugnancia y la inmundicia de aquel lugar horrible nunca serán borradas de mi memoria", era tan impresionante su visión, que imaginaba "que, en toda la creación, haya apenas un lugar más horrible que el sótano de un navío negrero". A más de esas miserias, las inclemencias del tiempo producían una navegación accidentada que enfermaba más a los cautivos. Baquaqua expresó su melancolía, su vivencia dolorosa en repetidas ocasiones a lo largo del escrito: "el desaliento se apoderó totalmente de mí [...] no soy capaz de describir mi desolación [...] quedamos desesperados de sufrimiento y de fatiga" (Moore, 1854, p. 40-57; Lara, 1988, p. 269284).

Los temores de los esclavos frente a los blancos, antes y durante la travesía, como la creencia de que se iba a hacer aceite con ellos, a arrancarles los ojos, a chuparles la sangre o a comérselos vivos, fueron frecuentes y motivaron también el suicidio (Barcia, 2007, p. 363364; Robb, 2007, p. 19-20). En Cartagena de Indias, Pedro Claver relata el testimonio de José Monzolo (1657), quien explicaba que los africanos creían que las banderas de los navíos, cuando eran rojas, estaban pintadas con la sangre de los negros, "este testigo vio a muchos de ellos que, asustados y desesperados por esto, se arrojaban al mar" (Aristizábal \& Splendiani, 2002, p. 223). "Era tan fuerte la creencia en el canibalismo blanco, que en el siglo XIX Robert Burton descubrió que incluso la costumbre europea de besar era atribuida, en Dahomey (hoy Benin), a propensiones caníbales" (Piersen, 1977, p. 147-159). 


\section{Todas las rudezas del cautiverio}

Se estudiarán en este apartado los casos donde el suicidio aparece como una consecuencia del cautiverio. En este conjunto de casos sobresalen varias motivaciones: aniquilarse para ser libre, matarse para huir de los castigos excesivos de los dueños, suicidarse por la nostalgia de un mundo perdido.

Generalmente, en el contexto de vida esclava, el acto suicida es interpretado como liberador, en el sentido de que permitía al esclavo huir de su condición de esclavitud. A menudo, en los relatos que se construyen para explicar este comportamiento, el deseo de libertad surge como principal motivación. Esto aparece con frecuencia en la prensa de la época. En el Estado de Sao Paulo, el esclavo Manoel se hizo una herida en la garganta y luego se mató con uno o dos tiros en la cabeza, porque, según personas cercanas, no quería vivir más en cautiverio. ${ }^{3}$ Refiere la Gazeta de Campinas (1887), que algunos testigos le escucharon decir en varias ocasiones que si no lograba fugarse, se mataría (Oliveira \& Oda, 2008, p. 377).

Se conoció también, por la prensa de Sao Paulo, el caso del esclavo Ambrosio, y de sus múltiples y furiosas tentativas por huir del cautiverio (1873). Ambrosio se evadió de la casa de sus dueños - negociantes de Campinas - y mató al empleado que intentó impedirlo. Fue alcanzado luego en Sorocaba, pero logró escapar de nuevo. Cuando por fin fue capturado se le envió a prisión, de donde se fugó tiempo después, con lo cual las personas que lo cogieron se alarmaron, pues Ambrosio había jurado matarlos. Fue recapturado en Botucatu, y hecho preso en Campinas, como pena por haber cometido dos homicidios y una tentativa. La historia del esclavo, de sus fugas y capturas, se hizo célebre en la región. Una vez en la prisión, realizó varias tentativas de suicidio, pero solo consiguió matarse el 12 de octubre de 1874, con una puñalada en el cuello (Oliveira \& Oda, 2008, p. 372).

Un caso más o menos semejante relata el Diário da Bahia en 1862. En la ciudad de Santo Amaro aparecieron, en los tanques de un ingenio, seis cadáveres, que correspondían a una madre y sus cinco hijos, que se encontraron amarrados. La esclava se había fugado y supo que iban a ir a capturarla. No queriendo vivir más en cautiverio, ató a sus hijos y los tiró al tanque para que se ahogaran, luego se lanzó ella. Un informe del delegado de policía da a conocer más detalles del caso. La esclava vivía huida desde hacía más de 25 años, período en el cual tuvo a sus hijos. Cuando murió el señor que los protegía, se desencadenó la persecución por parte de su "verdadero propietario", que quería no solo recuperarla a ella sino también a sus hijos. Viendo el retorno al cautiverio como ineludible, la mujer procedió de aquella trágica manera (Ferreira, 2004, p. 212-213).

En su recorrido, Baquaqua también intentó suicidarse cuando estaba en Pernambuco. El esclavo había sido comprado por un panadero que lo ponía a trabajar duramente en la construcción de una casa y, en ocasiones, a vender pan. Baquaqua, queriendo evitar el maltrato, intenta convertirse en el esclavo más hacendoso, solícito y obediente, pero cuando ve que su buen comportamiento no le salva de los ultrajes (ser buen esclavo no era garantía de buen

3 La fuente menciona que se dio "cuatro" tiros en la cabeza, pero quizá se trate de un error. 
trato), decide "volverse como los demás". Un día, su amo descubre que había vendido muy poco pan y que con el dinero de la venta se había comprado "uísque", por lo que fue golpeado muy severamente. Baquaqua le ruega que no lo castigue más, pero sus súplicas no son oídas. Ante ello, el esclavo anota que tenía tanta rabia "que le vino a la cabeza la idea de matar a su amo" y, luego, "suicidarme". Resolvió entonces ahogarse, pues "prefería morir que seguir siendo un esclavo". Corrió hasta el río y se arrojó al agua, pero como fue visto por algunas personas que estaban en un barco, fue rescatado. Sin embargo, Baquaqua se arrepiente de aquel proceder, y al narrar, tiempo después su periplo, ya convertido a la fe cristiana, agrega "agradecí a Dios por haber preservado mi vida e impedido que un acto tan perverso se consumase". Podría verse en esa expresión de arrepentimiento de Baquaqua el carácter de pecado que la muerte voluntaria merecía en su nueva religión (católica), pero en el Islam el suicidio también era reprobado, el suicida estaba condenado al infierno, donde sufriría un castigo doloroso e interminable 4 . Luego señala que tal proceder lo había llevado a reflexionar seriamente que "Dios se mueve por caminos misteriosos [...] todos sus actos son actos de benevolencia y misericordia" (Moore, 1854, p. 40-57; Lara, 1988, p. 275).

El maltrato puede asumir la forma del castigo desmedido por la comisión de una falta, o de agresión cuando no se le dan al esclavo los medios de subsistencia necesarios o cuando se le exige demasiado trabajo. Estas dos últimas situaciones le pasaron al esclavo Antonio, de 50 años. En Recife, según el registro policial del 3 de marzo de 1875, Antonio había intentado matarse ahogándose en el río, pero había sido rescatado por un canoeiro. Al ser interrogado por el jefe de policía explicó su acción diciendo que solo de esa forma podía "evitar la perversidad de su señor que, no atendiendo su flaqueza, le exigía el pago de una elevada cuantía por día y no lo alimentaba ni lo vestía" (Canario, 2011, p. 68-69).

La problemática del castigo siempre gira en torno al ejercicio del poder y del control, es un tema profundo y complejo. En el castigo se pone en relación violencia y esclavitud, donde la violencia se empleaba generalmente para garantizar la fuerza de trabajo y como instrumento para mantener el poder (Souza, 2004, p. 12-13). La rudeza debía servir como herramienta de sometimiento, ella estaba diseñada para controlar la vida de los esclavos y para situar las relaciones con sus amos y con la sociedad donde vivían (Souza, 2004, p. 12-13). Además, para que sirviera de advertencia a los otros esclavos sobre lo que les esperaba si contravenían las normas. Hay formas de punición y castigo cuya presencia puede parecer trivial en principio, pero cuya repetición constante llega tener repercusiones importantes, no solo sobre la salud física, sino también sobre la vida psíquica, generando gran sufrimiento. Igualmente, los gestos de desprecio, de humillación permanente marcan una dimensión significativa del maltrato, con consecuencias importantes para la problemática que aquí se explora, esas actitudes de abuso persistente producen efectos acumulativos nefastos.

Son múltiples los casos de suicidio que se presentan por motivos semejantes. Baste, como ilustración, el caso de María en Bahía, quien en 1864, huyó de sus amos y luego fue capturada. Ante tal situación María se tomó "una buena dosis de veneno" y antes de fallecer dijo

4 Corán 4: 29-30 
que se había envenenado "por su gusto, porque no quería vivir más y soportar el maltrato que le daba su señor" (Ferreira, 2004, p. 214).

Aunque por la naturaleza de la esclavitud el esclavo perdía el derecho a la libertad personal, no necesariamente perdía también todos sus derechos (Klein, 1966, p. 228-229). El esclavo iberoamericano estuvo bajo la jurisdicción de un régimen que procedía de la ley de esclavitud romana. En España y Portugal la esclavitud era una institución reconocida desde los tiempos pre-clásicos hasta el descubrimiento del Nuevo Mundo. Los pueblos ibéricos hacía mucho tiempo que aceptaban la individualidad y la personalidad del esclavo negro (Klein, 1966, p. 228-229).

Como se ha podido apreciar y como se verá en casos posteriores, era frecuente que los esclavos recurrieran a los tribunales de justicia para demandar a sus amos por razones varias: maltrato, deseo de manumisión, de ser vendido a otro amo, entre otros. Los esclavos intentaron utilizar los recursos legales, aún si eran limitados, para mejorar sus condiciones de vida y de trabajo (De la Fuente, 2004, p. 91-117). Es cierto que ante una situación de maltrato, el esclavo podía acudir a los tribunales para que cesara, sin embargo, es probable pensar que los abusos recurrentes podrían generar en él sensaciones de angustia, de aprensión, de miedo, que le impedían apelar a ese recurso, produciéndole una incapacidad para reaccionar.

Una variación de la relación suicidio esclavo-castigo, es la que se vislumbra cuando los esclavos se dan la muerte para escapar al castigo, es decir, cuando el esclavo se mata para evitarlo. Es posible pensar que anteriores experiencias de punición hacen que tema la severidad e inclemencia de la siguiente. Otra es aquella que se presenta cuando, al final de un proceso criminal, algunos esclavos, en lugar de esperar a que los funcionarios o autoridades judiciales les aplicaran la pena de muerte, deciden darse muerte ellos mismos.

La primera es la situación de los esclavos Antonio y Philippe de Sao Paulo. Antonio huyó de su amo y fue encontrado en la hacienda de otro propietario. Al ver que iría preso por su conducta, se propinó una puñalada, intentando matarse (en diciembre de 1879). Por su parte, Philippe también había huido y fue capturado, se hirió con un puñal cuando se le informó que iría preso por orden de su señor. Fue llevado al hospital en muy grave estado (en febrero de 1879) (Oliveira \& Oda, 2008, p. 377).

En Bahía se conocieron casos semejantes. Uno de los más célebres fue el intento de suicidio de una mujer con su hijo en 1864, porque la habían atrapado después de querer fugarse para evitar más maltrato (Ferreira, 2004, p. 211). En Salvador, la africana Camila, de 30 años, esclava de una pareja de africanos libertos, llamados Domingos y Guilhermina, que vivían en la Rua do Cais Dourado, intentó ahogarse con su hijo Marcos, de cinco meses. Cuando llevaba a cabo el acto suicida, la esclava y su hijo fueron rescatados por los transeúntes y conducidos por ellos ante el subdelegado de la parroquia del Pilar, donde Camila declaró haber tomado esa fatal decisión para liberarse por fin de "sus señores" quienes los maltrataban y exigían de ella servicios que no podía realizar. Domingos y Guilhermina fueron llamados a comparecer a la delegación, y -según anota el artículo de prensa- los dueños temían perder la esclava y su cría, "que quizá habían comprado después de años de trabajo como esclavos y luego como libertos", resolvieron, por consejo del funcionario, ponerlos en venta. Camila y su hijo fueron 
enviados a la casa de corrección y no fue posible saber más sobre su destino (Ferreira, 2004, p. 211).

Algo similar sucedió en Juiz de Fora (Minas Gerais) en 1863. A las 5 de la mañana, se suicidó, en una senzala de la Fazenda da Floresta, el esclavo Cypriano de 40 años de edad, perteneciente a Francisco de Barros Justino. El esclavo había comentado a sus compañeros de cautiverio que había sido castigado cruelmente, con un tronco en los pies durante más de un año; pero no dijo por qué. Un día, el capataz envió a Cypriano y a su compañero Manoel a buscar una azada y a regresar luego a la casa. Aprovechando la distracción de Manoel, Cypriano tomó un cuchillo y se hirió mortalmente (Amoglia, 1999, p. 3).

Una situación análoga es relatada por el delegado de la policía de Río de Janeiro, quien informó que en la hacienda Bocânia, el 15 de diciembre de 1881 se había hallado el cadáver de un hombre negro. Luego pudo constatarse que se trataba del esclavo Bertoldo, "quien estaba fugado desde el día 12 y se había suicidado ahogándose" (Moura, 2004, p. 382). Su muerte se atribuyó a los frecuentes castigos que había sufrido por parte de su amo Nogueira

En relación con la segunda variación, la de quien se mata antes de que sea ejecutada la pena de muerte, se conoció el caso de Eduardo, quien se suicidó el 4 de abril de 1851, cuando era llevado por un escolta de la Casa de Corrección de Bahía a la ciudad de Santo Amaro, donde se cumpliría su sentencia de muerte. De un momento a otro, el esclavo echó mano de un cuchillo y se degolló. El policía no supo explicar cómo había llegado el arma a las manos del condenado, pero dejaron en claro que con su muerte voluntaria, Eduardo "se sustrajo al cumplimiento de la condena, que le fuera impuesta por la justicia" (Ferreira, 2004, p. 210). Por desgracia, no ha sido posible saber qué delito había cometido. En este contexto, desde una visión religiosa y jurídica, fundada en la culpabilidad, la enmienda y la expiación, puede pensarse que la auto-eliminación se debe al arrepentimiento, pero desde otro punto de vista, puede interpretarse como la negación a recibir el castigo de la institución de justicia, de huir de la punición dada por ella, de no reconocerla.

\section{Por locura, banzo, desgano vital, traumatismo}

Alexander Falconbridge anotaba, a finales del siglo XVIII, que muchos africanos, al ser capturados, enloquecían (Falconbridge, 1788, p. 18). Cuando esa locura o "furia" era muy evidente, los esclavos eran abandonados, porque no podrían ser vendidos, sin embargo aquellos en quienes no era tan notoria la afección mental podían hacer el viaje, ser vendidos y trabajar al servicio de un amo, hasta que la locura se hacía evidente en varias formas, incluso en la auto-aniquilación.

En Bahía, la mucama del académico Antonio Andrade, fue hallada muerta, flotando frente al trapiche de la parroquia del Pilar. La esclava residía en la calle de Santo Antonio da Mouraria - parroquia de Santana -, y según su amo, la doméstica "sufría de alienación en ciertas fases de la luna" (Ferreira, 2004, p. 205). En la noticia de prensa se articula entonces un tema ancestral que une el suicidio con la locura y con la luna, a partir de la expresión del amo. 
En muchas civilizaciones se establece un lazo entre la luna y varios fenómenos humanos. La luna creciente, por ejemplo, aparece como signo de esperanza, mientras que la menguante invoca la extinción, la muerte y la desesperación; el día anuncia el posible éxito de las acciones humanas, mientras que en la noche habita el mal. La luna tiene una doble significación, es benéfica y maléfica; produce enfermedad y curación, el equilibrio y la locura.

El vínculo entre locura y muerte voluntaria es también puesto en evidencia en Sao Paulo, en 1871. Allí se encontró el cadáver del labrador negro Felisberto Claro d'Escobar, quien se había disparado con un revólver. A juicio de algunos testigos preguntados por la administración de justicia y recogidos por la Gazeta de Campinas, "era propenso a los trastornos mentales" (Oliveira \& Oda, 2008, p. 371-388).

El Jornal do Commercio (Rio de Janeiro) registra durante la segunda mitad del siglo XIX, varias muertes voluntarias asociadas a locura, como la de Valentim. Este último era esclavo de Faria y Miranda, establecidos en la Rua dos Lázaros, y sufría de una violenta fiebre y de delirios; era tratado por el Dr. Antonio Rodrigues de Oliveira. El periódico relata que 20 de mayo de 1872 a las 9 de la noche, Valentim tuvo un fuerte acceso de locura y se hirió con un golpe fatal en el cuello (Venâncio, 2005, p. 3).

En otras ocasiones se reconocía clara y explícitamente la locura como causa directa del suicidio como fue el caso de la negra Justina, de 50 años, esclava de Narciso da Silva Galharno, quien se mató, ahorcándose, el 8 de marzo de 1872 a la 1 de la tarde. El señor delegado de policía conoció del hecho, procedió a retirar el cadáver del lugar de los hechos y dejó señalado: "consta que la negra sufría de alienación mental" (Venâncio, 2005, p. 3). El esclavo Vital Emilio, de 40 años, habitante de Recife, se ahorcó en 1887, y su ceremonia fúnebre fue costeada por la cofradía de São Benedito, a la cual pertenecía, porque, según el Jornal do Recife, "hacía cierto tiempo que mostraba perturbaciones en sus facultades intelectuales" (Canario, 2011, p. 82).

Relacionado también con un estado de profunda perturbación anímica se encuentra el banzo. En Brasil se llamó banzo a la tristeza profunda en la cual caían muchos esclavos antes (cuando habían sido capturados y esperaban el traslado), durante o después de la travesía atlántica. De allí surgió el adjetivo banzeiro, como sinónimo de pensativo, estado de tristeza sin motivo (Moura, 2004, p. 63). Es interesante constatar la forma de nombrar esta tristeza o nostalgia, en Brasil se elige una palabra de origen africano, no portugués; y en América hispana se toma una palabra castellana, melancolía, un concepto proveniente de la cosmología y la medicina occidental. En tanto nostalgia por un mundo perdido, el banzo y la melancolía fija afectarían solo a los esclavos bozales, africanos recién llegados de su país. Muchas veces, los esclavos empezaban a desfallecer en las costas africanas y expiraban durante el viaje trasatlántico. Se enfermaban de melancolía; acurrucados, con la barbilla sobre las rodillas y los brazos alrededor de las piernas, rehusaban alimentos hasta que morian (Friedemann, 1993, p. 51).

Gilberto Freyre anota que en Brasil colonial los esclavos se suicidaban comiendo tierra (Freyre, 2006, p. 451), ahorcándose, envenenándose con hierbas y brebajes, y también a causa del banzo ("a saudade da África"). Algunos eran afectados por ello de tal manera ("tão banzeiros") que "parecían idiotas y permanecían penando" (Freyre, 2006, p. 553). Se suponía 
que el banzo era una enfermedad crónica, una nostalgia profunda que les causaba el temor de su propia muerte, que les parecía ineluctable. En el siglo XIX, obras como las del médico francés François Sigaud y del naturalista Carl F. von Martius, así como crónicas de viajeros europeos, difundieron la idea de una nostalgia fatal entre los esclavos. En estos relatos, las muertes voluntarias de los cautivos eran descritas como una forma pasiva de suicidio; por negarse a comer, morían de inanición y de tristeza. Dichos letrados atribuyen este deseo de muerte a una enfermedad relacionada con la melancolía por el cautiverio: la desesperación de ser violentamente arrancados de África, la rebelión contra la pérdida de la libertad, y las reacciones a penas severas e injustas (Oda, 2007, p. 347-348; Oliveira, 2007, p. 56).

En varias culturas de África se creía que, después de la muerte, el esclavo podría retornar a su tierra patria gracias a un proceso de resurrección. La creencia de que al morir, los esclavos volvían o renacían en su país natal, le restaba trascendencia subjetiva, aparentemente, al suicidio. Debido a esta idea, muchos amos llegaban a cortar las manos y la cabeza de los esclavos suicidas, para persuadir así a los demás de que los muertos al reencarnar en su tierra nativa no podrían comer, ver, oír ni hablar. Se sabe que a los esclavos de Haití les cortaban la nariz y las orejas para que la reencarnación no fuese apetecible a los sobrevivientes del suicida (Goulart, 1972, p. 124; López, 2005, p. 179-199; 2008, p. 779-790).

El algunas religiones africanas el culto a los ancestros era esencial. Los antepasados eran modelos de identificación y guardianes de la disciplina moral de la comunidad; garantizaban la continuidad entre la vida y la muerte, el pasado y el presente tanto individual como del grupo. El culto a los antepasados estaba vinculado con la forma como cada nación pensaba la naturaleza del universo y a las fuerzas que lo regían; se fundamentaba en la creencia de que la persona sobrevivía después de la muerte, de aquí el afán de algunas culturas de celebrar un ritual que incluyera ofrendas de ayuda al difunto y que le permitiera alabar apropiadamente a los espíritus en nombre de los parientes. El mundo de los vivos estaba en constante interacción con el mundo de los muertos, principalmente, con los antepasados y los jefes de clan fallecidos (Navarrete, 1995, p. 33).

En la mayor parte de las culturas africanas, los ancestros son intermediarios necesarios entre las divinidades secundarias y el hombre o entre Dios y el hombre. Se trata de una actitud adoptada por la conciencia colectiva para luchar contra la acción disolvente de la muerte y los efectos nefastos del desorden, de la cual ella es, a la vez, causa y efecto. En esas condiciones, el culto a los ancestros es trascendental, no existe ninguna actividad profana de importancia que no ponga a los vivos en relación con los muertos (Thomas, 1963, p. 410).

Esta relación con los muertos marca una suerte de solidaridad de los universos de los vivos y de los ancestros, y podría explicar el traumatismo que puede causar llevar a los africanos a lugares donde pierden su relación con sus muertos, pues quiebran el vínculo con su comunidad. En 1793, el abogado luso brasilero Luiz Antonio de Oliveira Mendes escribió una memoria sobre las enfermedades de los negros cautivos en diversas etapas del comercio de esclavos. ${ }^{5}$ Según su estudio, el banzo era una "pasión del alma" que afligía a los africanos

5 MENDES, Luiz Antonio de Oliveira. Memórias Econômicas da Academia Real das Ciências de Lisboa. Lisboa: Academia Real, 1812. 422p. 
esclavizados, un intenso resentimiento que podría ser causado por la nostalgia de su tierra natal, por amores perdidos, por injusticias y traiciones sufridas y principalmente, por la "cogitación profunda" sobre la pérdida de la libertad (Oda, 2007, p. 348). Sin embargo, el banzo no existía en el mismo grado, ni se manifestaba de la misma manera en todas las tribus africanas llevadas a América (Bastide, 1973, p. 67). La dolencia se manifestaba desde la travesía atlántica o después del arribo a tierra firme (Tardieu, 2007, p. 197).

Narra Oliveira Mendes la situación de Raimundo Jalama, comisario de las compañías de Pará y Pernambuco para la compra de esclavos en Angola, quien informó sobre el caso de una esclava que padecía la enfermedad. La esclava había sido traída con una niña de 7 u 8 años, a quien llamó Lucrecia. La madre padecía tal abatimiento y languidez por "efectos del banzo" que no quería comer nada, aunque se le ofrecieran los mejores platos. Al observar esta obstinación, Jalama le ofreció un premio a la niña si lograba averiguar la causa de tal tristeza. La niña contó luego que su madre tenía la certeza de que su marido, "a quien tanto amaba" la había entregado, a ella y a su hija, a los comerciantes de esclavos, como prenda. Al saber el motivo se le prometió buen trato, pero nada fue capaz de deshacer su congoja. "Sus ojos eran dos ríos, tenía permanentemente la cabeza entre las rodillas", siguió sin querer comer y, al cabo de algunos días, falleció (Oda, 2007, p. 356).

Más allá de las formas de nominación de esta tristeza por un mundo perdido, en el caso de los grupos africanos esclavizados, es importante vincular esta expresión con otra, a la cual se apeló muy frecuentemente para designar la desolación que produjo el violento proceso de conquista europeo en las comunidades indígenas americanas: el desgano vital (Sánchez, 1973, p. 76-77). La actitud de desgano vital sería provocada por el trauma que la conquista generó en el mundo indígena: desestructuración política, económica y social, servidumbre física, quiebre de las expresiones religiosas, nutrición escasa, ruptura con un mundo antiguo, heredado por los ancestros, que daba sentido a la existencia. Este abatimiento se evidenciaba también, pero no solamente, en lo que hoy llamaríamos suicidio, los indígenas se dejaban morir de hambre y de sed o se mataban de diversas maneras. Hay otro concepto, el de "traumatismo de la conquista" constituido para pensar las profundas transformaciones que generó en la vida indígena del Perú la conquista española, que podría traerse a colación para relacionarlo con el desgano y el banzo en el contexto de la trata. El traumatismo de la conquista, cuya amplitud aún es objeto de polémica, se entiende como "una especie de abandono, un hundimiento del universo tradicional" (Wachtel, 1992, p. 23) de los pueblos sometidos. Con la expresión se quiere señalar que la conquista española transformó el conjunto de los puntos de referencia, de certidumbres implícitas y explícitas, de identidades que apoyaban, desde hacía siglos, la existencia de los pueblos indígenas (Gruzinski, 1985, p. 411-433).

\section{Por amor, por venganza, por alcohol y como estrategia}

El amor-pasión es también reconocido como motivo de muerte voluntaria. En Bahía, el negro Francisco, músico, esclavo de Raimunda Porcina de Jesús, quien vivía en la parroquia de 
Santana, se quitó la vida el 18 de mayo de 1869. Francisco tocaba con frecuencia en las fiestas y era muy querido por sus amos y sus compañeros. En una ocasión, fue a tocar en una fiesta que duró hasta las once de la noche, al regresar a casa Francisco y algunos de sus compañeros tomaron café y se fueron a dormir. Esa misma noche Francisco se ahorcó. Su amigo, Antônio Caetano de Mello, esclavo y también músico, declaró como testigo que había oído que el motivo había sido una "pasión amorosa" (Ferreira, 2004, p. 216).

En la misma región, Alexandrina huyó de su amo (1871) para irse a vivir con su amante Vicente, quien era criollo y piragüista. En el momento de la captura, la esclava fue encontrada escondida en la casa de Vicente. Mientras la policía trataba de destrozar la puerta, ella tomó una porción de solimán (preparación de mercurio), pero no hubo tiempo para que hiciera efecto. Al preguntársele por su proceder, Alexandrina dijo que no quería separarse de su enamorado y que este le había recomendado que no regresara a la casa de su señor, porque "era mejor morir que ir a la cárcel, soportar azotes y otros castigos" (Ferreira, 2004, p. 213). Aquí, al parecer se mezclan las motivaciones amorosas con las del miedo al castigo.

El suicidio fue también una forma de venganza. Teniendo en cuenta el capital que los propietarios habían invertido en ellos, muchos esclavos se suicidaban "para vengarse de sus amos con el perjuicio que les producían". Varios dueños se endeudaban para poder adquirir esclavos, de ahí que en ocasiones su suicidio podía llevarlos a la ruina o causarles un gran perjuicio económico. ${ }^{6}$

El jefe de policía de Rio de Janeiro relató que en Valença, el 29 de mayo de 1880, se había suicidado, ingiriendo una pócima venenosa, el pardo Antônio, esclavo de Doña Caetana Augusta de Avelar, como venganza por haber sido acusado por su señora de andar envenenando animales y de haber intentado hacer lo mismo con personas de la familia de ella (Moura, 2004, p. 382).

También se puede considerar la tentativa de suicidio como un medio para lograr un objetivo específico, como una estrategia de negociación no-dicha, latente. Asimismo, puede ser una acción realizada para desviar la atención por otra falta grave. En relación con la administración de justicia, se conocieron situaciones en las cuales la tentativa de suicidio pretendía despistar al juez durante un proceso criminal. En relación con los amos, se tenía la pretensión de que si no se lograba llegar a un arreglo adecuado sobre determinada cuestión para el esclavo, este se mataría.

El deseo de negociación con los amos puede verse en el caso del esclavo Luiz (1854) quien huyó de su dueño, que residía en la ciudad de Santo Amaro (Bahía), importante centro azucarero, y fue capturado en Salvador, en la parroquia de Santo Antônio. Al preguntársele por el motivo de su huida, Luiz informa al delegado que tomó tal decisión porque su señor no quería venderlo, y añadió que si era obligado a regresar donde su dueño, se ahorcaría. No fue posible determinar si, efectivamente, Luiz lo hizo, sin embargo, la clara expresión de la intención aquí mostrada es significativa (Ferreira, 2004, p. 211). Con la amenaza de suicidio, el propósito es obtener cierto tipo de ganancia, una satisfacción directa o indirecta de un deseo

6 Ver suicidios por motivos semejantes a los ya expuestos en: Matos da Costa (2007) 
o aspiración del esclavo.

Como se anotó, los motivos de la muerte voluntaria pueden ser varios, uno aparece como "evidente", pero esconde otro más recóndito. Se conocían desde hacía tiempo los efectos de las bebidas embriagantes sobre la conducta violenta, se intuía aun borrosamente la relación entre consumo de alcohol y melancolía, lo que podía favorecer el comportamiento de autoagresión. Esta es la explicación que se da en el caso del suicidio de la esclava Rita, en Recife, sucedido en noviembre de 1871, por haberse tirado de uno de los pisos de un edificio en aquella población. El Diario de Pernambuco informó que, según el delegado de la policía que conoció el hecho, "la esclava fue llevada a practicar tan atentado por hallarse en estado de alienación mental a consecuencia de la embriaguez que se daba" (Canario, 2011, p. 130).

El agobio y el pánico a la enfermedad también aparecieron como origen del suicidio. La lepra fue una dolencia que producía miedo debido, quizás, a la deformidad, "al olor infecto" y a la creencia de que era una enfermedad maldita (Obregón, 1997, p. 139). En 1857, José Cândido de Carvalho, quien vivía en Juiz de Fora, salió con sus esclavos para que les trataran la elefancia de que sufrían (lepra). Todos los esclavos enfermos se quedaron en la casa de Eleuterio Venancio de Carvalho, primo de José Cândido. El esclavo Miguel, se sirvió de un cuchillo para matar a su esposa Rita y a sus tres hijos, antes de apuñalarse a sí mismo, en la nuca. En la mañana del 29 de mayo, se oyeron los fuertes gritos de los niños en la casa, Eleuterio envió a uno de sus esclavos con José Cândido a ver lo que pasaba. Al abrir la puerta, vieron muerta, caída en el suelo, a Rita. Cerca de su cuerpo estaban los niños, ensangrentados, heridos de muerte. Miguel, que había huido, fue luego encontrado en el puente de plantación de plátano, con una grave herida en el cuello y el cuchillo a su lado. Confesó haber cometido el múltiple asesinato y se abrió un proceso criminal en su contra. El testimonio de Miguel no pudo tomarse debido a que el acusado se había quedado sin voz, mudo. Se le inculpó de los delitos de homicidio y lesiones graves del código criminal, pero falleció antes de que el proceso avanzara. Quizás, la enfermedad sufrida por su familia puede haberle llevado a querer buscar un alivio más rápido (Amoglia, 1999, p. 4).

La epilepsia, en la Antigüedad llamada el "mal sagrado", porque se suponía consecuencia de una intervención divina, también motivó esta conducta y a menudo, la enfermedad también se vinculaba con la melancolía. El Diario de Pernambuco (Recife) informó el 24 de noviembre de 1880, que el esclavo Asterio se había lanzado a una locomotora en movimiento y fue llevado al Hospital Pedro II donde, antes de morir, había declarado que "no podía más soportar la vida". El Doctor José Carneiro, su propietario, comunicó el día siguiente al periódico que Asterio padecía de "epilepsia y que tenía úlceras en una de sus piernas" (Canario, 2011, p. 64) lo que, a su juicio, había producido su desesperación y su muerte.

Puede que el sufrimiento insoportable causado por la enfermedad precipite el acto mortal. Además, las dos enfermedades relacionadas aquí, la lepra y la epilepsia, conllevan una gran carga simbólica negativa, abierta a la inserción de consideraciones religiosas y morales que pueden hacer más penoso su padecimiento. 


\section{Consideraciones finales}

Sobre los motivos de la muerte voluntaria de los esclavos, se hace evidente que casi todos tienen una correlación con el estado de servidumbre. Pero este vínculo no es siempre evidente, no existe una relación explícita de causa-efecto. En ese sentido, el lazo directo que algunas veces se ha establecido entre servidumbre y suicidio, puede controvertirse, en el sentido de que no toda situación de sumisión lleva a la autoeliminación. No todos los seres sometidos a servidumbre se mataron, ni todos los cautivos enloquecieron y luego, se dieron muerte. El suicidio esclavo elude la explicación simple, siempre depende de la decisión que una persona toma en un contexto cultural y socio-económico específico, pero, aun así, el contexto nunca determina por completo la decisión del actor.

Cuando se explora este problema, el historiador se encuentra en una zona de penumbra, el funcionamiento mental es tan impenetrable en los hombres del presente como en los del pasado. La idea entonces no es llegar a conclusiones "verdaderas" sobre el auténtico por qué de la actuación fatal de los esclavos, sino analizar las significaciones socio-culturales que el relato de su muerte puede revelar, a partir de la manera como "los otros" (jueces, policías, familiares, amos, vecinos) atribuyen sentido al suicidio de los esclavos.

Así, ya se tratare de morir por la propia mano durante la travesía marítima, de matarse por miedo, de darse muerte por los crueles tratamientos y castigos de los que eran objeto en tierra firme; de suicidarse en un estado de alienación, de melancolía, por rencor, por venganza o por amor, los esclavos tuvieron motivos diversos para decidir terminar con su vida.

Los casos han mostrado la variedad de las experiencias de los esclavos, de sus expectativas, de sus formas de procesar la pérdida, las heridas, la servidumbre. Cada uno de ellos vive y asume de una forma muy diferente su experiencia, por más elementos comunes que se encuentren en la condición de cautiverio compartida.

En cierta forma, el acto suicida fue para el esclavo una manera de enfrentar, de imponer la propia voluntad sobre las circunstancias, un acto de autonomía individual, a través del cual se evidenciaba la necesidad de mantener su dignidad incluso cuando fue avasallado por la desesperación, el abatimiento o el dolor. Muchos sustituyeron el empeño de soportar por el ansia de morir. En otras ocasiones, se trataba de tomar el control de la propia vida para terminar con ella. Pensar en el acto suicida del esclavo no solo como resistencia directa al avasallamiento, supone también la reafirmación de su condición humana.

\section{Referencias Bibliográficas}

AGUIRRE, Gonzalo. La población negra de México. México: Fondo de Cultura Económica (FCE), Universidad Veracruzana, 1989. 375p.

AMOGLIA, Ana Maria Faria. Um suspiro de liberdade: suicidio de escravos no Municipio de Juiz de Fora (1830-1888). Boletim de História Demográfica. São Paulo, n. 18, nov. 1999. Disponible en: <http://historia_demografica.tripod.com/bhds/umsuspiro.htm>. Acceso en: 16/05/2018. 
ARGOUSE, Aude. Presentación. Revista Historia y Justicia. Santiago de Chile, n. 1, p. 1-3, oct./ abr. 2013.

ARISTIZABAL, Tulio \& SPLENDIANI, Ana María. Proceso de beatificación y canonización de san Pedro Claver. Bogotá: Centro Editorial Javeriano, 2002. 593p.

BÄHR, Andreas. Between "Self-Murder" and "Suicide": The Modern Etymology of Self-Killing. Journal of Social History. Oxford, v. 46, n. 3, p. 620-632, 2013.

BARCIA, Manuel. Suicide. In: TOYIN, Falola \& WARNOCK, Amanda (Eds.). Encyclopedia of the Middle Passage. London: Greenwood Publishinf Group, p. 363-364, 2007.

BASTIDE, Roger. Saudade e Banzo. In: Estudos Afro-Brasileiros. São Paulo: Perspectiva, p. 4853, 1973. Mantener esta referencia y suprimir la de arrriba.

BRANCACCIO, Maria Teresa; ENGSTROM, Eric \& LEDERER, David. The Politics of Suicide: Historical Perspectives on Suicidology before Durkheim. An Introduction. Journal of Social History, v. 46, n. 3, p. 607-619, 2013.

CANARIO, Ezequiel David do Amaral. "É mais uma scena da escravidão": suicídios de escravos na cidade do Recife, 1850-1888. Dissertação (Mestrado em Historia). Programa de Pós-Graduação em História, Universidade Federal de Pernambuco, Pernambuco, 2011. 170p.

CHALHOUB, Sidney. Visões da liberdade: Uma história das últimas décadas da escravidão na Corte. São Paulo: Companhia das Letras, 2011. 351p.

DE LA FUENTE, Alejandro. Su "único derecho": los esclavos y la ley. Debate y perspectivas: Cuadernos de historia y ciencias sociales. Madrid, n. 4, p. 7-22, 2004.

DEVISSE, Jean. Les Africains, la mer et les historiens. Cahiers d'études africaines. Paris, v. 29, n. 115-116, p. 397-418, 1989.

DURKHEIM, Émile. Le suicide: Étude de sociologie. París: Ancienne Librairie Germer Baillière Et Cie, 1897. 486p.

FALCONBRIDGE, Alexander. An Account of the Slave Trade on the Coast of America. London: J. Philiphs, George Yard, Lombard - Street, 1788. 62p.

FALRET, Jean-Pierre, De l'hypochondrie et du suicide: considérations sur les causes, sur le siége et le traitement de ces maladies, sur le moyen d' en arreter les progres et d' en prevenir le développement, París: Chez Croullebois; Libraire de la Société de Médecine, 1822. 519p.

FERREIRA, Jackson. "Por hoje se acaba la lida." Suicidio escravo na Bahia (1850-1880). AfroÁsia. Salvador, n. 31, p. 216-217, 2004.

FIGUEREIDO, Cândido de. Suicídio. Suicida. In: _-__-__. Novo Diccionário da Língua Portuguesa. 1913. Disponible en: <http://dicionario-aberto.net/estaticos/about.html>. Consultado el 01/06/2018.

FLORENTINO, Manolo. Em costas negras: uma história do tráfico de escravos entre a África e o Rio de Janeiro. São Paulo: Companhia das Letras, 1997. 290p. 
FLORENTINO, Manolo; VIEIRA, Alexandre \& DOMINGUES, Daniel. Aspectos comparativos do tráfico de africanos para o Brasil. Séculos XVIII e XIX". Afro-Ásia. Salvador, n. 31, p. 83-126, 2004.

FREYRE, Gilberto. Casa-grande \& senzala: Formação da familia brasileira sob o regime da economía patriarcal. São Paulo: Global Editora, 2006 [1933]. 719p.

FRIEDEMANN, Nina S. de. La saga del negro: Presencia africana en Colombia. Bogotá: Universidad Javeriana, 1993. 117p.

GODINEAU, Dominique. S' abréger les jours. Le suicide en France au XVIII siècle. Paris: Armand Colin, 2012, 336p.

GOODY, Jack. Death, Property and the Ancestors: A Study of the Mortuary Customs of the Lodagaa of West Africa. London: Routledge Library Editions, 1962. 452p.

GOULART, José Alipio. Da fuga ao suicídio: aspectos da rebeldía dos escravos no Brasil. Rio de Janeiro: Conquista, 1972. 294p.

GRIFFIN, Miriam. Philosophy, Cato, and Roman Suicide: I. Greece \& Rome. Cambridge, v. 33, n. 1, p. 64-77, 1986.

GRUZINSKI, Serge. La red agujerada. Identidades étnicas y occidentalización en el México colonial (siglo XVI- XIX). América Indígena. México, DF, v. 46, n. 3, p. 411-434, jul./sep. 1985.

HARRIS, Chapin Aaron. A dictionary of dental science, biography, bibliography, and medical terminology. Philadelphia: Lindsay \& Blakiston, 1849. 780p.

KLEIN, Herbert. Sociedades esclavistas en las Américas. Un estudio comparativo. Desarrollo Económico. Buenos Aires, v. 6, n. 22-23, p. 227-245, 1966.

KNEELAND, Linda Kay, African American Suffering and Suicide under Slavery. Thesis (Master of Arts in History). College of Graduate Studies, Montana State University, Bozeman, 2006.

LA ROSA, Gabino. Historia y memoria: sociedad, cultura y vida cotidiana en Cuba 1878-1917. Centro de Investigación y Desarrollo de la Cultura Cubana Juan Marinello, Programa de Estudios de América Latina y el Caribe, Universidad de Michigan: La Habana, 2003.

LARA, Silvia. Biografia de Mohammah G. Baquaqua. Revista Brasileira de História. São Paulo, v. 8, n. 16, p. 269-284, 1988.

LÓPEZ, Adrián. Melancholia, Slavery, and Racial Pathology in Eighteenth-Century Cuba. Science in Context. Tel-Aviv, v. 18, n. 2, p. 179-199, 2005.

LÓPEZ, Adrián. Nostalgia y esclavitud en la era de las revoluciones. Revista Latinoamericana de Psicopatología Fundamental. São Paulo, v. 11, n. 4, p. 779-790, 2008.

LOVEJOY, Paul. Comparación de la vida de dos musulmanes en América: Muhammad Kaba Saghanaghu y Mahommah Gardo Baquaqua. Estudios de Asia y África. Ciudad de Mexico, v. XLIII, n. 1, p. 13-32, ene./abr. 2008.

MATOS DA COSTA, María Fernanda. A morte e o morrer em Juiz de Fora: Transformações 
nos costumes fúnebres, 1851-1890. Dissertação (Mestrado em História). Instituto de Ciências Humanas, Universidade Federal de Juiz de Fora, Juiz de Fora, 2007. 145p.

M'BOKOLO, Elikia. África negra: História e Civilizações até ao Século XVIII. Salvador: Casa das Áfricas; EUFBA, 2009. 754p.

MIDY, Franklin. Les Congos à Saint-Domingue: de l'imaginaire au réel. Ethnologies. St. Johns, NL, v. 28, n. 1, p. 173-201, 2006.

MOORE, Samuel (Ed.). Mahommah G. Baquaqua, Biography of Mahommah G. Baquaqua. A native of Zoogoo, in the interior of Africa, Detroit: George E. Pomey and Co, Tribune Office, 1854. 102p.

MOSQUERA, Claudia; PARDO, Mauricio \& HOFFMAN, Odile. Afrodescendientes en las Américas: Trayectorias sociales e identitarias. Bogotá: Universidad Nacional de Colombia, Instituto Colombiano de Antropología e Historia (ICANH), Institu de Recherche pour le Dévéloppement, Instituto Latinoamericano de Servicios Legales Alternativos, 2002. 609p.

MOURA, Clóvis. Dicionário da Escravidão negra no Brasil. São Paulo: EdUSP, 2004. 440p.

NAVARRETE, María Cristina. Prácticas religiosas de los negros en la colonia: Cartagena, siglo XVII. Cali: Universidad del Valle, 1995. 174p.

OBREGÓN, Diana. Medicalización de la lepra: una estrategia nacional. Anuario Colombiano de Historia Social y de la Cultura. Bogotá, n. 24, p. 139-165, 1997.

ODA, Ana María, O banzo e outros males: O páthos dos negros escravos na Memória de Oliveira Mendes. Revista Latinoamericana de Psicopatología Fundamental. São Paulo, v. 10, n. 2, jun. 2007.

OLIVEIRA, Saulo e ODA, Ana María. O suicídio de escravos em São Paulo nas últimas duas décadas da escravidão. História, Ciências, Saúde. Manguinhos, RJ, v. 15, n. 2, p. 371-388, 2008.

OLIVEIRA, Saulo Veiga, O suicídio de escravos em Campinas e na província de São Paulo (1870-1888), Dissertação (Mestrado em Ciências Médicas). Faculdade de Ciencias Médicas, Universidade Estadual de Campinas, Campinas, SP, 2007. 225p.

ORTIZ, Fernando. Los negros esclavos: estudios sociológicos y de derecho público. Revista Bimestre Cubana, La Habana, 1916.

PIERSEN, William. White Cannibals, Black Martyrs: Fear, Depression and Religious Faith as Causes of Suicide Among New Slaves. The Journal of Negro History. Chicago, v. 62, n. 2, p. 147-159, abr./1977.

PUIG-SAMPER, Miguel Angel. El suicidio esclavo en el mundo Atlántico. In: NARANJO OROVIO, Consuelo (Ed.). Esclavitud y diferencia racial en el Caribe Hispano. Madrid, Ediciones Doce Calles, S.L., p. 71-87, 2017.

REDIKER, Marcus. O navio negreiro: uma história humana. São Paulo: Companhia das Letras, 2011. 448p.

RICH, Jeremy et al. Dictionary of African Biography. Oxford: Oxford University Press, 2012. 
$3384 p$.

ROBB, Erika. African Fears of Cannibalism. In: TOYIN, Falola \& WARNOCK, Amanda (Eds.). Encyclopedia of the Middle Passage. London: Greenwood Publishinf Group, p. 19-20, 2007.

SÁNCHEZ, Nicolás. La población de América Latina desde tiempos precolombinos al año 2000. Madrid: Alianza Editorial, 1973. 312p.

SÁNCHEZ, Nicolás. La población de la América colonial española. In: BETHELL, Leslie (Ed.). Historia de América Latina: 4 América Latina Colonial: Población, sociedad y cultura. Barcelona: Crítica, p. 15-38, 1990.

SANDOVAL de, Alonso. Un tratado sobre la esclavitud. Reimpresión. Madrid: Alianza, 1987 [1627]. 614p.

SMALLWOOD, Stephanie. Saltwater Slavery: A Middle Passage from Africa to American. Diaspora: Harvard University Press, 2008. 288p.

SNYDER, Terri. Suicide, Slavery, and Memory in North America. The Journal of American History. Oxford, v. 97, n. 1, p. 39-62, 1 jun. 2010.

SOUZA, Benedito, Cuerpos, horcas y látigos: Esclavitud y espectáculo punitivo en el Brasil decimonónico. Tesis (Doctorado en Antropología Social y Cultural). Universidad Autónoma de Barcelona, Barcelona, 2004. 427p.

STEVENSON, Ian. The Belief in Reincarnation Among the Igbo of Nigeria. Journal of Asian and African Studies. Toronto, v. 20, n. 1-2, p. 13-30, 1985.

TARDIEU, Jean Pierre. La «métempsycose» des esclaves noirs aux Amériques espagnoles (XVle -XVIIIe siècles). Outre-mers. Paris, v. 94, n. 356, p. 195-207, 2007.

TEMPĖRE, Delphine. Marins et missionnaires face aux dangers des navigations océaniques au XVIle siècle: Catastrophes, recours matériels et méditations spirituelles. e-Spania. Paris, n. 12, dez. 2011. Disponible en: <http://e-spania.revues.org/20832>. Acceso en: 16/05/2018.

THOMAS, Louis- Vincent. En hommage à Louis-Vincent Thomas. Le cadavre. Études sur la mort. Paris, n. 129, p. 11-22, 2006.

THOMAS, Louis- Vincent. Remarques sur quelques attitudes négro-africaines devant la mort. Revue Française de Sociologie. Paris, v. 4, n. 4, p. 395-410, 1963.

TOYIN, Falola \& WARNOCK, Amanda. Encyclopedia of the Middle Passage. Londres: Greenwood Publishinf Group, 2007. 426p.

VALENCIA, Carlos Eduardo. Alma en boca y huesos en costal: Una aproximación a los contrastes socio-económicos de la esclavitud. Santafé, Mariquita y Mompox 1610-1660. Bogotá: Instituto Colombiano de Antropología e Historia, 2003. 214p.

VALENCIA, Carlos Eduardo. En procura de la libertad en las dos puntas de un hilo: la manumisión entre los esclavos. En: ALZATE ECHEVERRI, Adriana; FLORENTINO, Manolo y VALENCIA, Carlos Eduardo (Eds.). Imperios ibéricos en comarcas americanas: Estudios regionales de historia colonial brasileña y neogranadina. Bogotá; Rio de Janeiro: Editorial Universidad del Rosario; 
Universidade Federal do Rio de Janeiro, p. 237-285, 2008.

VENÂNCIO, Renato P. Banzo: a melancolia negra. A depressão e o suicídio dos escravos eram fatos corriqueiros. Revista Aventuras na Historia. São Paulo, no 18, 2005.

WACHTEL, Nathan. La Vision des vaincus: Les Indiens du Pérou devant la Conquête espagnole. París: Folio- Gallimard, 1992 [1971]. 432p.

Enviado em: 01 de junho de 2018.

Aprovado em: 08 de outubro de 2018. 